\title{
Alternate release of different target species based on the same gold nanorods and monitored by cell imaging
}

Shenna Chen, ${ }^{a}$ Haowen Huang, ${ }^{a *}$ Lingyang Zhang, ${ }^{a}$ Yun Chen, ${ }^{\mathrm{b}}$ Xuanyong Liu ${ }^{\mathrm{c} *}$

${ }^{a}$ Key Laboratory of Theoretical Organic Chemistry and Function Molecule, Ministry of Education, School of Chemistry and Chemical Engineering, Hunan University of Science and Technology, Hunan Provincial University Key Laboratory of QSAR/QSPR, Xiangtan, 411201, China.

${ }^{\mathrm{b}}$ State Key Laboratory of Chemo/Biosensing and Chemometrics, College of Chemistry and Chemical Engineering, Hunan University, Changsha, 410082, China

${ }^{\mathrm{c}}$ State Key Laboratory of High Performance Ceramics and Superfine Microstructure, Shanghai Institute of Ceramics, Chinese Academy of Sciences, Shanghai 200050,

China

Corresponding authors

Haowen Huang: hhwn09@163.com, Tel:+86-731-58290045, Fax: +86-731-58290509

Xuanyong Liu: xyliu@ mail.sic.ac.cn, Tel:+86-21-52412409, Fax: +86-21-52412409 


\section{Abstract}

In this study, a strategy for load and release of different kinds of molecules on the same gold nanorods (GNRs) was developed. An anticancer drug, doxorubicin hydrochloride (DOX), was firstly chemically conjugated on the GNRs. To efficiently load another type of target molecules DNA on the same GNRs, a polyelectrolyte Poly (ethylene imine) (PEI)was adsorbed on the GNR@DOX to form GNR@DOX@PEI. Then, the positive charge GNR@DOX@PEI allows the GNR conjugates to interact with negative charged DNA by an electrostatic interaction, enabling their full conjugation. A platform to load two kinds of target molecules conjugated on the same GNRs was fabricated. On the other hand, selective and sequential release of the different target species may be triggered by chemical reaction and near infrared (NIR) laser. The release of DOX was achieved by $\mathrm{Na}_{2} \mathrm{~S}_{2} \mathrm{O}_{3}$ reacting with GNRs and the discharge of DNA conjugated on the GNR@DOX@PEI was accomplished by local-heating using NIR laser triggered release. Furthermore, the selective and alternate release of different target species from the GNRs inside MCF-7 cells was monitored by fluorescent imaging, providing a potential synergistic cancer treatment.

Keywords: gold nanorods, drug release, breast cancer, NIR laser irradiation, fluorescent imaging 


\section{Introduction}

The use of multiple drugs, known as combination therapy, which simultaneously use two or more drugs can be synergistically effective for diseases such as malaria, cancer, and others [1-5], showing enhanced therapeutic efficacy over the two independent treatments. Physical and chemical methods are the common release ways. Chemotherapy is one of the most commonly used cancer therapeutic approaches [6-8]. Meanwhile, the photothermal induced by near infrared (NIR) irradiation has a great potential for photodynamic therapy, considering that NIR irradiation in the $800-1100$ $\mathrm{nm}$ region can penetrate deeper tissues and cause less photo-damage [9-11]. Recently, nanoscale carriers have gained attraction, providing a possibility for release of different drugs [12-14]. However, the selective release of drugs beyond two species or even changing the order of release is challenge. A controllable and sophisticated manner in release of each species may lead to a highly synergistic effect and to the expansion of the therapeutic window for anticancer reagents, which could minimize side effects.

Latest advances in biocompatible nanomaterials and biotechnology open a promising field toward the development of biosensor, drug delivery, cell targeted vectors and photothermal therapy [15-20]. As elongated nanoparticles, gold nanords (GNRs) with unique optical properties depending on their size and shape are attracting extensive scientific interest [21-25]. GNRs can generate site-selective local heat shock, and they have great potential as an engineerable platform for thermo-chemo combination cancer therapy $[26,27]$. The multifunctional GNRs were 
believed to act as good platform not only for biosensing with high sensitivity but also for thermo-chemo combination cancer therapy.

In this work, two kinds of target molecules were conjugated on the same GNRs, on which the doxorubicin hydrochloride (DOX) and DNA were loaded by covalent bonding and electrostatic interaction, respectively. Then, successfully selective release of DOX and DNA triggered by different fashions was approached. Furthermore, the selective and alternate release of different species from the GNRs inside MCF-7 cells was monitored by fluorescent imaging, providing a potential synergistic cancer treatment.

\section{Materials and methods}

\subsection{Materials}

Cetyltrimethylammonium bromide $(\mathrm{CTAB}), \mathrm{HAuCl}_{4} \cdot 4 \mathrm{H}_{2} \mathrm{O}$, ascorbic acid, sodium thiosulfate, silver nitrate, were purchased from Sinopharm Chmical Reagent Co., Ltd. (Shanghai, China). N-Hydroxysuccinimide (NHS), N-ethyl-N-[(dimethylamino) propyl]carbodiimide (EDC), doxorubicin hydrochloride (DOX), Poly(ethylene imine)

(PEI, MW=1800) were purchased from Aladdin Industrial Inc. 11-Mercaptoundecanoic acid (MUA) was purchased from J\&K scientific Ltd. The plasmid DNA of green fluorescence protein (GFP) was purchased from Shanghai Gene Pharma Co., Ltd. All of the chemicals, unless mentioned otherwise, were of analytical reagent grade and used as received. Ultrapure water was used in cell experiment and doubly distilled was used in other experiments. 


\subsection{Load and release of DOX, DNA and FITC on GNRs}

GNRs were synthesized using a seed-mediated silver-assisted growth method [28, 29]. The activation of GNRs was carried out according to the previous protocol [30]. $100 \mu \mathrm{L}$ of $0.1 \mathrm{mg} / \mathrm{mL}$ DOX was added to the activated GNRs dispersion. 30 min later, the redundant DOX was discarded by centrifuging. Subsequently, $50 \mu \mathrm{L}$ of $2 \mathrm{mg} / \mathrm{mL}$ PEI was added to the resulted GNR@DOX, 1 hour later, the GNR@DOX@PEI conjugate was obtained by centrifuging. Then, the GNR@DOX@PEI conjugate was dispersed in the doubly distilled water. At last, $50 \mu \mathrm{L}$ of $0.1 \mathrm{mg} / \mathrm{mL}$ DNA was added to 1 mL of GNR@DOX@PEI solution to form GNR@DOX@PEI@DNA conjugate. The absorption spectra of GNRs in these processes were monitored by UV-visible spectrometry.

Near-infrared (NIR) irradiation treatment was carried out by $808 \mathrm{~nm}$ laser (400 mW).The GNR@DOX@PEI@DNA conjugate was treated by laser for 10min, and an identical sample without laser irradiation acts as control. The characteristic fluorescence of fluorescein isothiocyanate (FITC) was used to monitor the FITC release and the DNA release was monitored by UV absorption. On the other hand, $\mathrm{Na}_{2} \mathrm{~S}_{2} \mathrm{O}_{3}(0.01 \mathrm{M}, 30 \mu \mathrm{L})$ was added to the mixture solution to liberate the DOX.

\subsection{MTT assay}

Cytotoxicity was performed by standard 3-(4, 5-dimethylthiazol-2-yl) - 2, 5-diphenyltetrazolium bromide (MTT) assay. For this assay, MCF-7 cells were plated at a density of $5 \times 10^{3}$ cells per well in a 96-well plate (Nunc, USA) and cultured for 24 h. After the cells were incubated with varying concentration $\mathrm{Na}_{2} \mathrm{~S}_{2} \mathrm{O}_{3}$ at $24 \mathrm{~h}$ and $48 \mathrm{~h}$, 
the wells were washed with PBS. Then, $20 \mu \mathrm{L}$ of MTT $(5 \mathrm{mg} / \mathrm{mL}$, Sigma-Aldrich, USA) was added to each well, and the cells were further incubated at $37^{\circ} \mathrm{C}$ for $4 \mathrm{~h}$. The MTT-formazan generated by live cells was dissolved in $150 \mu \mathrm{L}$ of dimethyl sulfoxide (DMSO, Sigma-Aldrich, USA) to measure the absorbance at $492 \mathrm{~nm}$ by an enzyme labeling instrument (BIO-TEK, ELX 800, USA).

\subsection{Cellular Imaging}

MCF-7 cells in 2 mL RPMI 1640 were cultured on six-well plates with a destiny of $1.5 \times 10^{5}$ cells/well. After $12 \mathrm{~h}$ incubation, the medium was replaced by the mixture of free-serum RPMI 1640 and GNR@DOX@PEI@FITC conjugates solution.6 h later, the residual conjugates in the solution were washed with PBS and replaced with fresh RPMI 1640, and then the culture dishes were exposed to NIR laser for 3 min and 10 min, separately. After irradiation, the cells in each dish were incubated for 40 h. 220 $\mu \mathrm{L} 0.1 \mathrm{M}$ and $220 \mu \mathrm{L} 0.025 \mathrm{M} \mathrm{Na}_{2} \mathrm{~S}_{2} \mathrm{O}_{3}$ were added in the culture dishes for another 6 h. Finally, the cells were washed with PBS then the cells were fixed with $4 \%$ paraformaldehyde (PFA, Bio Basic Inc, USA) for fluorescence microscope (GX71, OLYMPUS, Japan).

\subsection{Experimental instrumentation}

Transmission electron microscopy (TEM) was performed on a Tecnai G2 20 (USA) transmission electron microscope (TEM) operating at $100 \mathrm{kV}$. Absorption spectra of the GNR dispersion were measured using Lambda 35 (PerkinElmer, USA). 


\section{Results and discussion}

\subsection{Load of target molecules based on the same GNRs}

Fig. 1A shows the TEM image. The corresponding absorption spectrum shown Fig. 1B displays transverse peak of localized surface plasmon resonance (LSPR) at 520 $\mathrm{nm}$ and longitudinal plasmon wavelength (LPW) at $791 \mathrm{~nm}$. The load of DOX and DNA on the same GNRs was performed by covalent bonding and electrostatic interaction. As shown in Scheme 1, DOX was first immobilized on the GNRs by taking the advantage of the affinity reaction between GNRs and thiol compounds. The GNRs easily react with alkanethiols to form a self-assembled monolayer (SAM) on them for attachment of recognition agents. As one of efficient anticancer drugs, DOX has $-\mathrm{NH}_{2}$ groups and readily react with the $-\mathrm{COOH}$ groups of MUA attached on GNRs to form covalent bonding with the help of EDC and NHS. As a result, the DOX was loaded on the surface of GNRs and formed the conjugate of GNR@DOX. The significant change of UV-vis absorption spectra of DOX aqueous solution before and after interacting with GNRs indicates that DOX molecules were successfully attached onto the GNRs, displayed as curves $a$ and $b$ in Fig. 1C. After the conjugation of DOX, the unreacted DOX was completely removed by centrifuging for 3 times. The high surface area to volume ratio of GNRs is advantageous for loading other molecules on the particle surface, leaving sufficient space to attach recognition molecules and thus enhance targeting to the desired location. Further load of DNA on the GNR@DOX was performed through electrostatic interaction on the surface of the GNRs. To efficiently adsorb the DNA, a polyelectrolyte PEI mixed with the 
GNR@DOX to form GNR@DOX@PEI. Then the oppositely charged DNA conjugated to GNR@DOX@PEI with an evident change of zeta potential from 70.8 $\mathrm{mV}$ to $33.7 \mathrm{mV}$. Meanwhile, the LPW of GNRs sensitively responds to the change in refractive index caused by DNA adsorption. As a result, a manifest red-shift of LPW (28nm) was occurrence, whereas the transverse plasmon wavelength remained unchanged (Fig. 1D), which confirm the successful conjugation of the DNA on GNR@DOX@PEI. Neither distinct broadening nor tailing of the LSPR band was observed during the process of PEI coating and DNA conjugation. GNR@DOX@PEI@DNA conjugates were further characterized by TEM, indicating the nanoparticles were not aggregated (Fig. S1 shown in supplementary materials). Furthermore,GNR@DOX@PEI@DNA conjugates were found to be stable for a few weeks in water without any agglomeration.

\subsection{Release of target molecules from the same GNRs}

Owing to the high efficiency of the energy conversion from light to local heating, GNRs have been widely developed as a new kind of local-heating mediator for NIR-triggered release, phototherapies for tumor treatment [31-33]. As reported previously, under strong pulse laser irradiation, the GNRs underwent a shape transformation into nanoparticles with a smaller aspect ratio or even nanospheres, depending on the irradiation power or/and irradiation time [34]. Herein, prior to exploring the possibility of remotely NIR continuous wave laser triggered target molecules release, we evaluated the stability of bare GNRs after a continuous NIR laser irradiation $(808 \mathrm{~nm}$ ) for $15 \mathrm{~min}$ by comparing the change in the longitudinal 
SPR band. No detectable change of LPW was found, suggesting that the GNRs are stable under the intensity of irradiation.

The laser was used to investigate the efficiency of release of DNA from the GNR@DOX@PEI@DNA.The GNR@DOX@PEI@DNA conjugates were irradiated under the laser for 10 min. Compared with the initial GNR@DOX@PEI@DNA conjugates, a significantly decreased absorption intensity ascribed to the DNA was found (curves $a$ and $b$ in Fig.2A), which elucidate the DNA was clearly released from the GNR@DOX@PEI@DNA conjugates under the 808 nm laser irradiation, and about $40 \%$ of the DNA loaded on GNRs was released.

DOX has strong red fluorescence which may serve as an indicator of DOX released from the GNR@DOX@PEI@DNA. $\mathrm{Na}_{2} \mathrm{~S}_{2} \mathrm{O}_{3}$ has been found to leach Au or Ag from ores and can react with gold nanoparticles to form soluble complex compounds [35, 36]. Oral $\mathrm{Na}_{2} \mathrm{~S}_{2} \mathrm{O}_{3}$ is usually as maintenance therapy for calcific uremic arteriolopathy, calciphylaxis in clinical practice $[37,38]$. In addition, there has been growing interest in the initiation of intravenous $\mathrm{Na}_{2} \mathrm{~S}_{2} \mathrm{O}_{3}$ as an adjunctive treatment in nonuremic patients with refractory calciphylactic ulcers [39]. In this study, $\mathrm{Na}_{2} \mathrm{~S}_{2} \mathrm{O}_{3}$ acts as the chemical agent for corroding the surface of GNRs to release the DOX attached on the GNRs. In this process, $\mathrm{Na}_{2} \mathrm{~S}_{2} \mathrm{O}_{3}$ was added to the GNR@DOX@PEI@DNA solution after laser irradiation. A characteristic fluorescence of DOX was expectedly found in the supernatant solution after centrifuge, as shown in Fig.2B. It is obvious that the DOX discharged from GNRs is dependent on the reaction time between GNR@DOX@PEI@DNA and $\mathrm{Na}_{2} \mathrm{~S}_{2} \mathrm{O}_{3}$. The percent of released DOX is around 92\% 
when reaction time is $1 \mathrm{~h}$. Doxorubicin is an anthracycline molecule analogue to the DNA, having the ability to insert adjacent base pairs of DNA, damage DNA. In this work, the DOX was immobilized on GNRs by 4'-amino group of DOX attached to the linker MUA to form GNR-MUA-DOX. MUA-DOX might be discharged from the surface of GNR when GNRs react with $\mathrm{Na}_{2} \mathrm{~S}_{2} \mathrm{O}_{3}$. The previous studies demonstrated that proper derivates of DOX by conjugation of 4'-amino group can effectively damage the cancer cell [40-42]. A comparison of the released MUA-DOX from GNRs in the MCF-7 cells at different stages is displayed in Figure S2. The discharged MUA-DOX could hardly affect the cell viability after 1 hour. However, most of the cells were dead and damage after 24 hours. This means the MUA conjugated on DOX may not affect the antitumor drug effect.

Meanwhile, GNRs after treatment with $\mathrm{Na}_{2} \mathrm{~S}_{2} \mathrm{O}_{3}$ was characterized by TEM shown in Fig. S3, which illustrates the experimental condition was not clearly change morphology of GNRs. These results illustrate that the DNA and DOX might be selectively released from the GNR@DOX@PEI@DNA via laser irradiation and chemical reaction, respectively.

\subsection{Cytotoxicity study}

As one of the most important factors to evaluate biomaterials, biological security should be considered before bio-application in vivo. The as-prepared GNRs were coated with a cationic surfactant stabilizer CTAB which might be cytotoxic at higher concentration $(0.2 \mathrm{M})$. The results shown in Fig. S4 indicate that the cytotoxicity is remarkably decreased with the decrease of the concentration of CTAB. It implies that 
the cytotoxicity may be attributed to the excess CTAB in solution. After the conjugation of DOX, GNR@DOX was subsequently coated with a layer of PEI polymer. The aims of the coating are two reasons: Firstly, it is to pack the CTAB and prevent the surfactant desorption, and the excess CTAB from nanorod synthesis can be removed with successively washing. Secondly, the toxicity of GNRs before and after PEI coating might be compared using a standard colorimetric assay (MTT) with MCF-7 cells, as shown in Fig. 3A. For the GNR@DOX, the cell viability is less than $40 \%$ after incubation for $24 \mathrm{~h}$, which exhibits remarkable cytotoxicity. It should be noted that after conjugation with targeted PEI, the viability of cells incubated with GNR@DOX@PEI are as high as $80 \%$ at the same concentration and incubation time, implying that the GNR@DOX coated with PEI greatly reduce the cytotoxicity.

Another consideration is the effect of laser irradiation time on cell viability. Different time of laser irradiation $(0,1,4,7,10,15 \mathrm{~min})$ was chosen to investigate the irradiation effect. What is certain is that the longer irradiation may facilitate to release DNA from the nanocarriers, however, the longer irradiation enables temperature increase of modified GNRs [43-46], leading to the damage of cells. As shown in Fig. $3 \mathrm{~B}$, when the irradiation time is more than $10 \mathrm{~min}$, a sharp decrease of cell viability would occur. Thus, $10 \mathrm{~min}$ is a reasonable irradiation time to irradiate MCF-7 cells for DNA releasing from GNR@DOX@PEI@DNA conjugates.

As aforementioned description, the release of DOX from nanorods would be implemented by the chemical reaction of $\mathrm{Na}_{2} \mathrm{~S}_{2} \mathrm{O}_{3}$ with GNRs. Various concentrations of $\mathrm{Na}_{2} \mathrm{~S}_{2} \mathrm{O}_{3}$ were used to explore the $\mathrm{Na}_{2} \mathrm{~S}_{2} \mathrm{O}_{3}$ effect on the cell viability. Evidently, 
the higher concentration $(0.1 \mathrm{M})$ results in low cell viability (Fig. 3C). Whereas, when the concentration is less than $0.01 \mathrm{M}$, the cell viability is high, and the influence of different concentrations of $\mathrm{Na}_{2} \mathrm{~S}_{2} \mathrm{O}_{3}$ on the cells shows negligible cytotoxicity.

\subsection{Different target species delivery and release in breast cancer cells}

Scheme 1 shows the delivery and alternate release of two target molecules in breast cancer cells by different fashions. To examine the delivery and release of the two target species from the GNR conjugates in the cells, the fluorescence distribution was investigated in MCF-7 cells. The fluorescence characteristics of DOX and DNA of GFP have been utilized to monitor its localization (Fig. S5). However, it can be seen that the whole cells exhibit very week green fluorescence with the exception of small spots of strong fluorescence. It is well known that the DNA expresses to protein should be carried out in the nucleus of cell. It is possible that few GNRs enter into the nucleus of the MCF-7 cells, and most of the GNR@DOX@PEI@DNA conjugates still stay in the cytoplasm, which the released DNA cannot express GFP. To confirm that the observed green fluorescence results from laser-induced dissociation of the GNR@DOX@PEI@DNA conjugates, an identical sample of MCF-7 cells without laser irradiation was used as control, which shows no any green fluorescence throughout these cells. To further validate the feasibility of this method and monitor the process, DNA was replaced by FITC in the fluorescent imaging. FITC is a kind of green fluorescence dye with negative charge and it may conjugate on the GNRs similar to DNA.

The cellular uptake efficiency and distribution of GNR@DOX@PEI@FITC 
conjugates have been monitored in MCF-7 cells using fluorescent microscopy. Being an intrinsic fluorescent molecule, DOX shows red fluorescence at excitation wavelength of $480 \mathrm{~nm}$ and emission at $590 \mathrm{~nm}$ at room temperature. After the uptake of GNR@DOX@PEI@FITC conjugates, the MCF-7 cells were incubated with $\mathrm{Na}_{2} \mathrm{~S}_{2} \mathrm{O}_{3}$. At the cellular level, GNR@DOX@PEI@FITC conjugates can easily enter cancer cells because of their relatively small size and can accumulate in the cancer cells. Fig. 4 shows the relationship between fluorescence intensity of DOX in the cells and the increased reaction time. This observation illustrates a gradient release of DOX from the GNRs in response to the concentrations of $\mathrm{Na}_{2} \mathrm{~S}_{2} \mathrm{O}_{3}$, suggesting the release of amount of drug are controllable. Different laser irradiation duration was explored and the irradiated time was chosen for $3 \mathrm{~min}$ and $10 \mathrm{~min}$, respectively. The fluorescence intensity of cells shown in Fig. 5 indicates the amount of released FITC was lower after 3 min irradiation, and a clear enhanced fluorescence occurred with the irradiation time up to $10 \mathrm{~min}$. The fluorescence intensity of MCF-7 cells is apparently dependent upon the irradiation duration.

The alternate release of the two target species conjugated on the same nanocarrier in the MCF-7 cells was investigated through chemical reaction and NIR laser irradiation, as shown in Fig. 6. The release order of the two species can be regulated according to the requirement of the treatment. That is to say, DOX may first be released from the GNRs by chemical reaction and the released amount of the DOX is dependence on the amount of $\mathrm{Na}_{2} \mathrm{~S}_{2} \mathrm{O}_{3}$ and reaction time. Moreover, DOX and FITC may be alternately released from the same GNRs through controlling the trigger 
ways, as shown in Scheme 1. Recently, there were many reports that the combination of different drugs achieves a good treatment efficacy. However, the side effects of various combinations have invoked concerns, for example, irritation of the blood vessels and mucous membranes, short circulation half-life, and poor bioavailability [47-50]. Considering that anticancer drugs damage leukocytes with time-dependence, control and sequential release different anticancer drugs might succeed in achieving the synergistic cancer treatment and immunity promotion. Sequential multiple drug delivery loaded on the same nanocarrier may provide a viable strategy to regulate multiple cellular signaling pathways by activating cell death in cancer cells without affecting normal cells and tissues [51, 52].

\section{Conclusions}

In conclusion, we developed a strategy for load and release of different target species on the same GNRs. Firstly, two target species were conjugated on the same GNRs, on which DOX and DNA were loaded by covalent bonding and electrostatic interaction, respectively. Secondly, selective and sequential release of these different target species may be triggered by different fashions. The release of DOX was achieved by $\mathrm{Na}_{2} \mathrm{~S}_{2} \mathrm{O}_{3}$ reacting with GNRs and the discharge of DNA conjugated on the GNR@DOX@PEI was accomplished by local-heating using NIR laser. Furthermore, the selective and alternate release two species inside MCF-7 cells based on the same GNRs was successfully monitored by fluorescent imaging. The strategy for load and sequential release of different species conjugated on GNRs may provide a possibility for selective release of different drugs and perspective in synergistic 
efficiency of cancer treatment.

\section{Acknowledgements}

This work was supported by National Natural Science Foundation of China (21375036, 21173074), National Science Foundation for Distinguished Young Scholars of China (51525207), Hunan Provincial Natural Science Foundation of China (14JJ7054), the Innovation Platform Open Funds for Universities in Hunan Province (13K090).

\section{References}

[1] P. Colombo, F. Sonvico, G. Colombo and R. Betteini, Pharm. Res. 26 (2009) 601-611.

[2] A. M. Gravett, W. M. Liu, S. Krishna, W. C. Chan, R. K. Haynes, N. L. Wilson and A.G. Dalgleish, Cancer Cnemoth Pharm. 67 (2011) 569-577.

[3] Y. Wang, S. Ma, Z. Xie, H. Zhang, Colloid Surface B 116 (2014) 41-48.

[4] J. Nam, W. G La, S. Hwang, Y. S. Ha, N. Park, N. Won, S. Jung, S. H. Bhang, Y. J. Ma, Y. M. Cho, M. Jin, J. Han, J. Y. Shin, E. K. Wang, S. G. Kim, S. H. Cho, J. Yoo, B. S. Kim and S. Kim, ACS Nano 7 (2013) 3388-3402.

[5] M. S. Chen, X. Y. Zhu and D. Y. Yan, RSC Adv. 3 (2013) 13399-13405.

[6] Y. N. Zhong, F. H. Meng, C. Deng and Z. Y. Zhong, Biomacromolecules 15 (2014) 1955-1969.

[7] J. L. Wu, C. Q. Wang, R. X. Zhuo, S. X. Cheng, Colloid Surface B 123 (2014) 498-505.

[8] C. T. Yu, M. J. Zhou, X. J. Zhang, W. J. Wei, X. F. Chen and X. H. Zhang, 
Nanoscale 7 (2015) 5683-5690.

[9] R. Weissleder, Nat. Biotechnol. 19 (2001) 316-317.

[10]A. Vogel and V. Venugopalan, Chem. Rev. 103 (2003) 577-644.

[11]Y. Y. Li, T. Wen, R. F. Zhao, X. X. Liu, T. J. Ji, H. Wang, X. W. Shi, J. Shi, J. Y. Wei, Y. L. Zhao, X. C. Wu and G. J. Nie, ACS Nano 8 (2014) 11529-11542.

[12]S. Moghassemi and A. Hadjizadeh, J. Control. Release 185 (2014) 22-36.

[13]C. He, K. Lu, D. Liu and W. Lin, J. Am. Chem. Soc. 136 (2014) 5181-5184.

[14]Y. Yang, D. Pan, K. Luo, L. Li and Z. Gu, Biomaterials 34 (2013) 8430-8443.

[15]Q. Hu, P. Katti and Z. Gu, Nanoscale 6 (2014) 12273-12286.

[16]H. Jin, X. Liu, R. Gui, Z. Wang, Colloid Surface B 128 (2015) 498-505.

[17]J. H. Joo and J. S. Lee, Anal. Chem. 85 (2013) 6580-6586.

[18]X. L. Sun, X. L. Huang, X. F. Yan, Y. Wang, J. X. Guo, O. Jacobson, D. B. Liu, L. P. Szajek, W. L. Zhu, G. Niu, D. O. Kiesewetter, S. H. Sun and X. Y. Chen, ACS Nano 8 (2014) 8438-8446.

[19]R. Venkatesan, A. Pichaimani, K. Hari, P. K. Balasubramanian, J. Kulandaivel and K. Premkumar, J. Mater. Chem. B 1 (2013) 1010-1018.

[20]A. R Guerrero, N. Hassan, C. A. Escobar, F. Albericio, M. J Kogan, E. Araya, Nanomedicine 9 (2014) 2023-2039.

[21]H. Huang, S. Chen, F. Liu, Q. Zhao, B. Liao, S. Yi and Y. Zeng, Anal. Chem. 85 (2013) 2312-2319.

[22]C. Kinnear, D. Burnand, M. J. D. Clift and A. F. M. Kilbinger, Angew. Chem. Int. Edit. 53 (2014) 12613-12617. 
[23]Q. K. Liu, M. G. Campbell, J. S. Evans and I. I. Smalyukh, Adv. Mater. 26 (2014) $7178-7184$.

[24]K. X. Zhang and X. L Shen, Analyst 138 (2013) 1828-1834.

[25]Z. Y. Wang, S. F. Zong, J. Yang, J. Li and Y. P. Cui, Biosens. Bioelectron. 26 (2011) 2883-2889.

[26]Z. J. Zhang, J. Wang, X. Nie, T. Wen, Y. L. Ji, X. C. Wu, Y. L. Zhao and C. Y. Chen. J. Am. Chem. Soc. 136 (2014) 7317-7326.

[27]H. Y. Chen, X. M. Chi, B. W. Li, M. Zhang, Y. X. Ma, S. Achilefu and Y. Q. Gu. Biomater. Sci. 2 (2014) 996-1006.

[28]C. J. Murphy, T. K. Sau, A. M. Gole, C. J. Orendorff, J. Gao, L. Gou, S. E. Hunyadi and T. Li, J. Phys. Chem. B 109 (2005) 13857-13870.

[29]B. Nikoobakht and M. A. El-Sayed, Chem. Mater. 15 (2003) 1957-1962.

[30]H. W Huang, F. Liu, S. W. Huang, S. S. Yuan, B. Liao, S. J. Yi, Y. L. Zeng and P. K. Chu, Anal. Chim. Acta. 755 (2012) 108-114.

[31]A. Agarwal, M. A. Mackey, M. A. El-Sayed and R. V. Bellamkondat, ACS Nano 2011, 5, 4919-4926.

[32]J. Wang, B. Dong, B. Chen, Z. Jiang and H. Song, Dalton Trans. 41 (2012) 11134-11144.

[33]A. M. Alkilany, L. B. Thompson, S. P. Boulos, P. N. Sisco and C. J. Murphy, Adv. Drug Deliver Rev. 64 (2012) 190-199.

[34]A. Wijaya, S. B. Schaffer, I. G. Pallares and K. Hamad-Schifferli, ACS Nano 3 (2009) 80-86. 
[35]M. G. Aylmore and D. M. Muir, Miner. Eng. 14 (2001) 135-174.

[36]T. Lou, L. Chen, Z. Chen, Y. Wang, L. Chen and J. Li, ACS Appl. Mater. Inter. 3 (2011) 4215-4220.

[37]S. U. Nigwekar, S. M. Brunelli, D. Meade, W. Wang, J. Hymes and E. Lacson Jr, Clinical journal of the American Society of Nephrology 8 (2013) 1162-1170.

[38]M. Brucculeri, E. Rullan, A. Zanchi and A. Marcotte, Hemodialysis International 18 (2014) 531-535.

[39]C. Fernandes, B. Maynard and D. Hanna, Journal of Cutaneous Medicine and Surgery, 18 (2014) 356-360.

[40]S. J. F. Kaptein, T. D. Burghgraeve, M. Froeyen, B. Pastorino, M. M. F. Alen, J. A. Mondotte, P.t Herdewijn, M. Jacobs, X. de Lamballerie, D. Schols, A. V. Gamarnik, F. Sztaricskai and J. Neyts, Antimicrobial Agents and Chemotherapy 54 (2010) 5269-5280.

[41]N. V. Ayala-Nuñz, P. Jarupathirun, S.J.F. Kaptein, J. Neyts and J. M. Smit, Antiviral Research 100 (2013) 238-245.

[42]B. S. Chhikara, N. S. Jean, D. Mandal, A. Kumar and K. Parang, European Journal of Medicinal Chemistry 46 (2011) 2037-2042.

[43]H. Jin, X. Liu, R. Gui, Z. Wang, Colloid. Surface B 128 (2015) 498-505.

[44]H. Tang, H. Kobayashi, Y. Niidome, T. Mori, Y. Katayama, T. Niidome, J. Control. Release 171 (2013) 178-183.

[45]T. Okuno, S. Kato, Y. Hatakeyama, J. Okajima, S. Maruyama, M. Sakamoto, S. Mori, T. Kodama, J. Control. Release 172 (2013) 879-884. 
[46]D. B. Pacardo, B. Neupane, G. Wang, Z. Gu, G. M. Walker, F. S. Ligler, Anal. Bioanal. Chem. 407 (2015) 719-725.

[47]X. Liu, W. S. H. Paul, Q. Li and L. W. Chan, Journal of Controlled Release 116 (2006) 35-41.

[48]T. A. Hill, S. G. Stewart, C. P. Gordon, S. P. Ackland, J. Gilbert, B. Sauer, J. A. Sakoff and A. McCluskey, ChemMedChem 3 (2008) 1878-1892.

[49]J. Shi, A. R. Votruba, O. C. Farokhzad and R. Langer, Nano Letters (10) 2010 $3223-3230$.

[50]S. J. Bell, C. M. Fam, E. A. Chlipala, S. J. Carlson, J. I. Lee, M. S. Rosendahl, D. H. Doherty and G. N. Cox, Bioconjugate Chemistry 19 (2008) 299-305.

[51]S. Narayanan, U. Mony, D. K. Vijaykumar, M. Koyakutty, B. Paul-Prasanth and D. Menon, Nanomedicine: Nanotechnology, Biology, and Medicine 11 (2015) 1399-1406.

[52]B. N. P. Kumar, N. Puvvada, S. Rajput, S. Sarkar, S. K. Das, L. Emdad, D. Sarkar, P. Venkatesan, I. Pal, G. Dey, S. Konar, K. R. Brunt, R. R. Rao, A. Mazumdar, S. C. Kundu, A. Pathak, P. B. Fisher and M. Mandal, Journal of Materials Chemistry B 3 (2015) 90-101.

\section{Figures and Captions}


Scheme 1. Schematic illustration of load and alternate release of drugs in breast cancer cells.

Fig. 1. TEM image of GNRs (A) and the corresponding absorption spectrum (B). (C) Absorption spectra acquired from GNR@DOX@PEI@DNA before (a) and after (b) laser irradiation. (D) is the fluorescence of DOX after GNR@DOX@PEI@DNA reacting with $\mathrm{Na}_{2} \mathrm{~S}_{2} \mathrm{O}_{3}$.

Fig. 2. Release of different species from GNRs by different ways: (A) absorption spectra acquired from GNR@DOX@PEI@DNA before (a) and after (b) laser irradiation, (B) is the fluorescence of DOX after GNR@DOX@PEI@DNA reacting with $\mathrm{Na}_{2} \mathrm{~S}_{2} \mathrm{O}_{3}$.

Fig. 3. Cell viability assays on MCF-7 cells. (A) different stages of loading-drug on GNRs versus cell viability; (B) irradiated time versus cell viability after NIR laser; (C)various concentrations of $\mathrm{Na}_{2} \mathrm{~S}_{2} \mathrm{O}_{3}$ versus cell viability.

Fig. 4. DOX release by addition of various concentration of $\mathrm{Na}_{2} \mathrm{~S}_{2} \mathrm{O}_{3}$. The concentration of $\mathrm{Na}_{2} \mathrm{~S}_{2} \mathrm{O}_{3}$ was $0 \mathrm{M}(\mathrm{a}), 0.0025 \mathrm{M}$ (b), and 0.01M (c). [Bright-filed (a $\left.\mathrm{b}_{1}, \mathrm{c}_{1}\right)$, dark-filed $\left(\mathrm{a}_{2}, \mathrm{~b}_{2}, \mathrm{c}_{2}\right)$, and overlay $\left.\left(\mathrm{a}_{3}, \mathrm{~b}_{3}, \mathrm{c}_{3}\right)\right]$. 
Fig. 5. Fluorescence microscopy images of FITC release from GNR@DOX@PEI@FITC by NIR laser irradiation. The irradiated time was 0 min (a), $3 \min (\mathrm{b})$, and $10 \min (\mathrm{c})$. [dark-filed $\left(\mathrm{a}_{1}, \mathrm{~b}_{1}, \mathrm{c}_{1}\right)$, bright-filed $\left(\mathrm{a}_{2}, \mathrm{~b}_{2}, \mathrm{c}_{2}\right)$, and overlay $\left.\left(\mathrm{a}_{3}, \mathrm{~b}_{3}, \mathrm{c}_{3}\right)\right]$

Fig. 6. Fluorescence microscopy images of two kinds of target molecules released alternately in MCF-7 cells. (a) The reaction of $\mathrm{Na}_{2} \mathrm{~S}_{2} \mathrm{O}_{3}$ with cells before NIR irradiation. (b) The NIR irradiation before the reaction of $\mathrm{Na}_{2} \mathrm{~S}_{2} \mathrm{O}_{3}$ with cells. The irradiation time was $10 \mathrm{~min}$ and the concentration of $\mathrm{Na}_{2} \mathrm{~S}_{2} \mathrm{O}_{3}$ was $0.01 \mathrm{M}$. [Fluorescence images of DOX $\left(a_{1}, b_{2}\right)$, fluorescence images of FITC $\left(a_{2}, b_{1}\right)$, bright-filed $\left(\mathrm{a}_{3}, \mathrm{~b}_{3}\right)$, and overlay $\left.\left(\mathrm{a}_{4}, \mathrm{~b}_{4}\right)\right]$. 


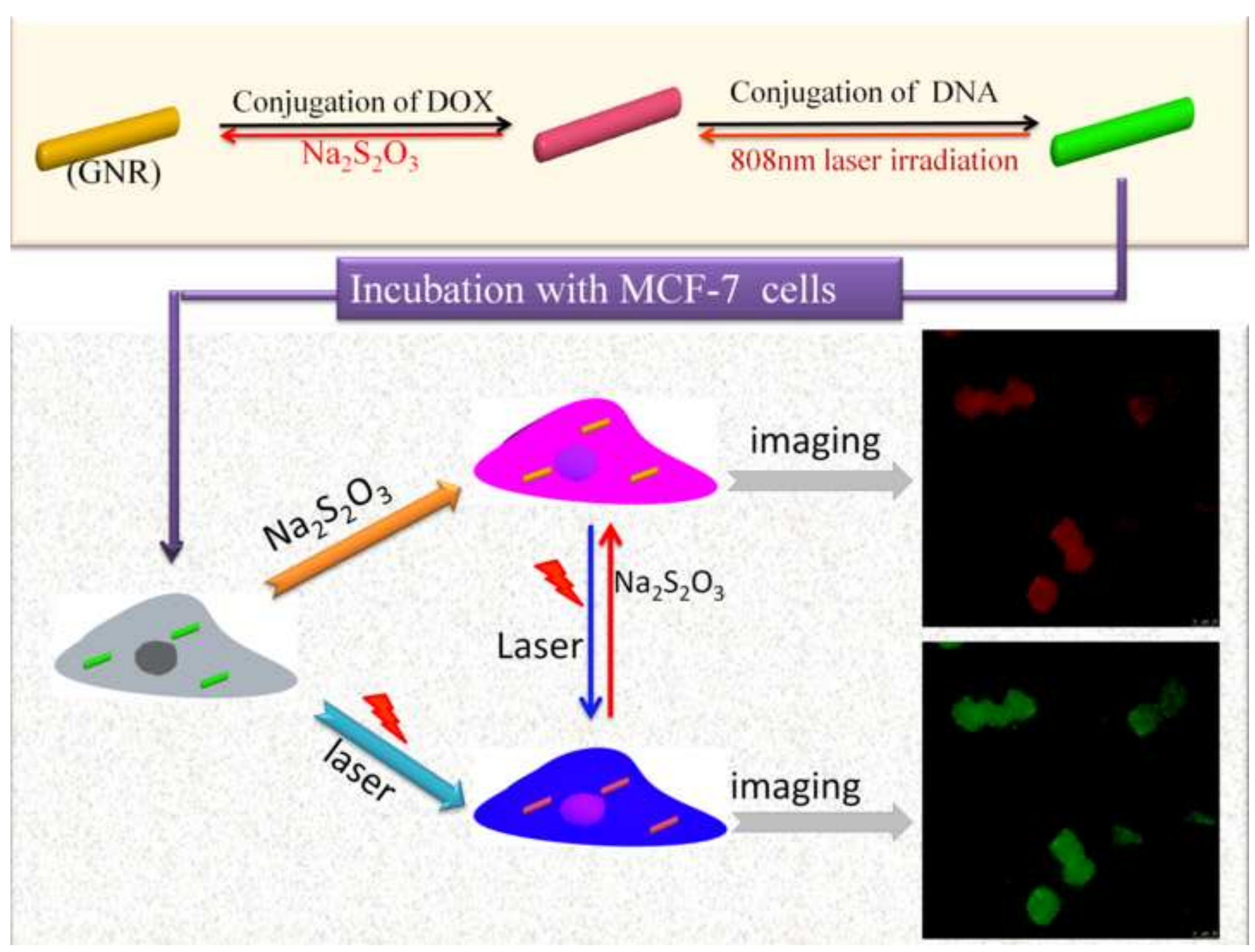



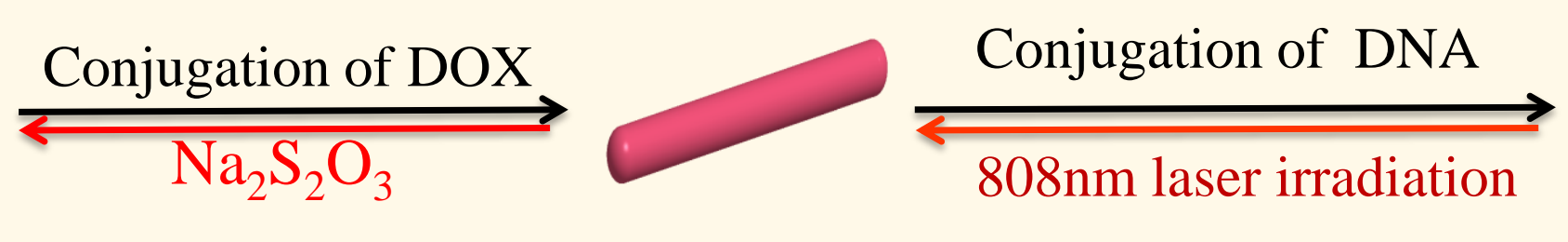

\section{Incubation with MCF-7 cells}
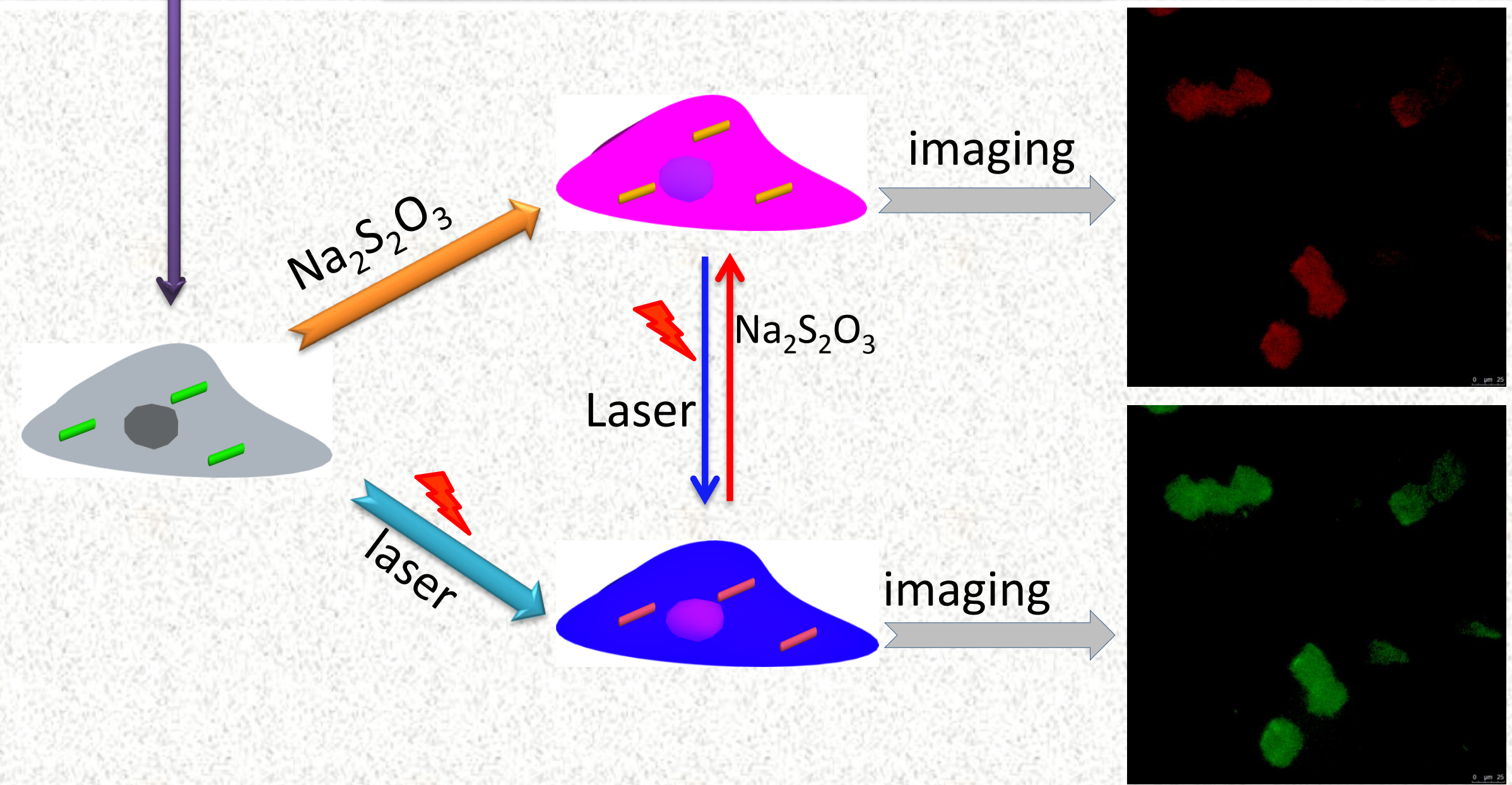

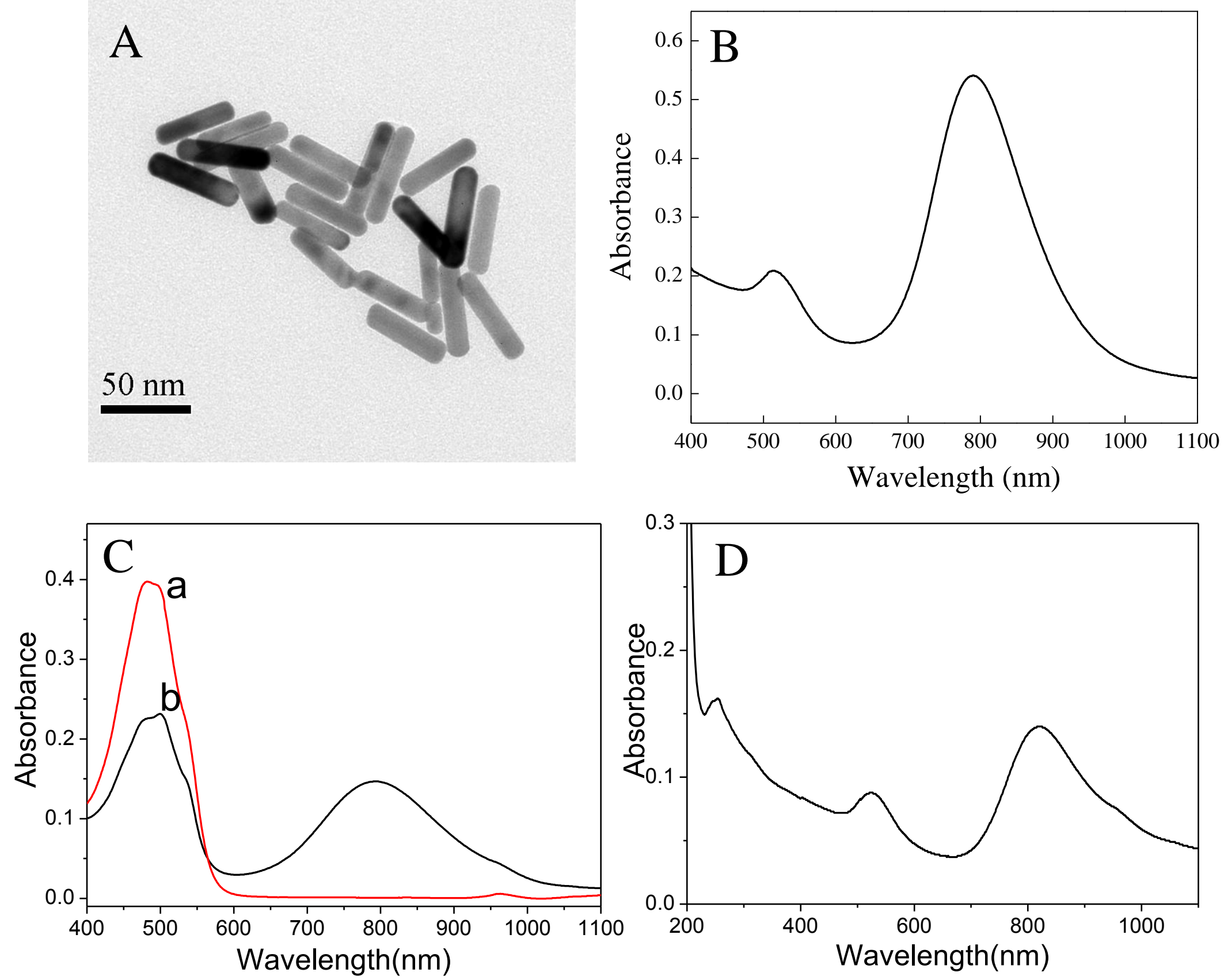

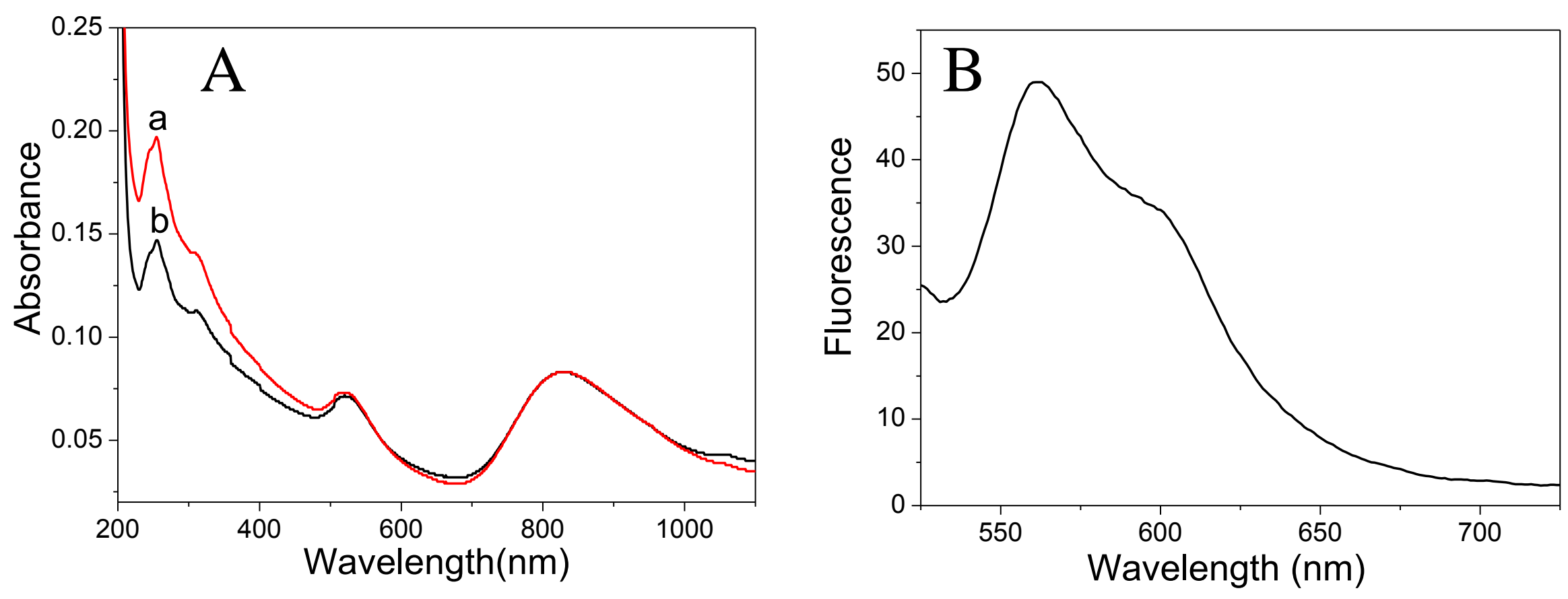

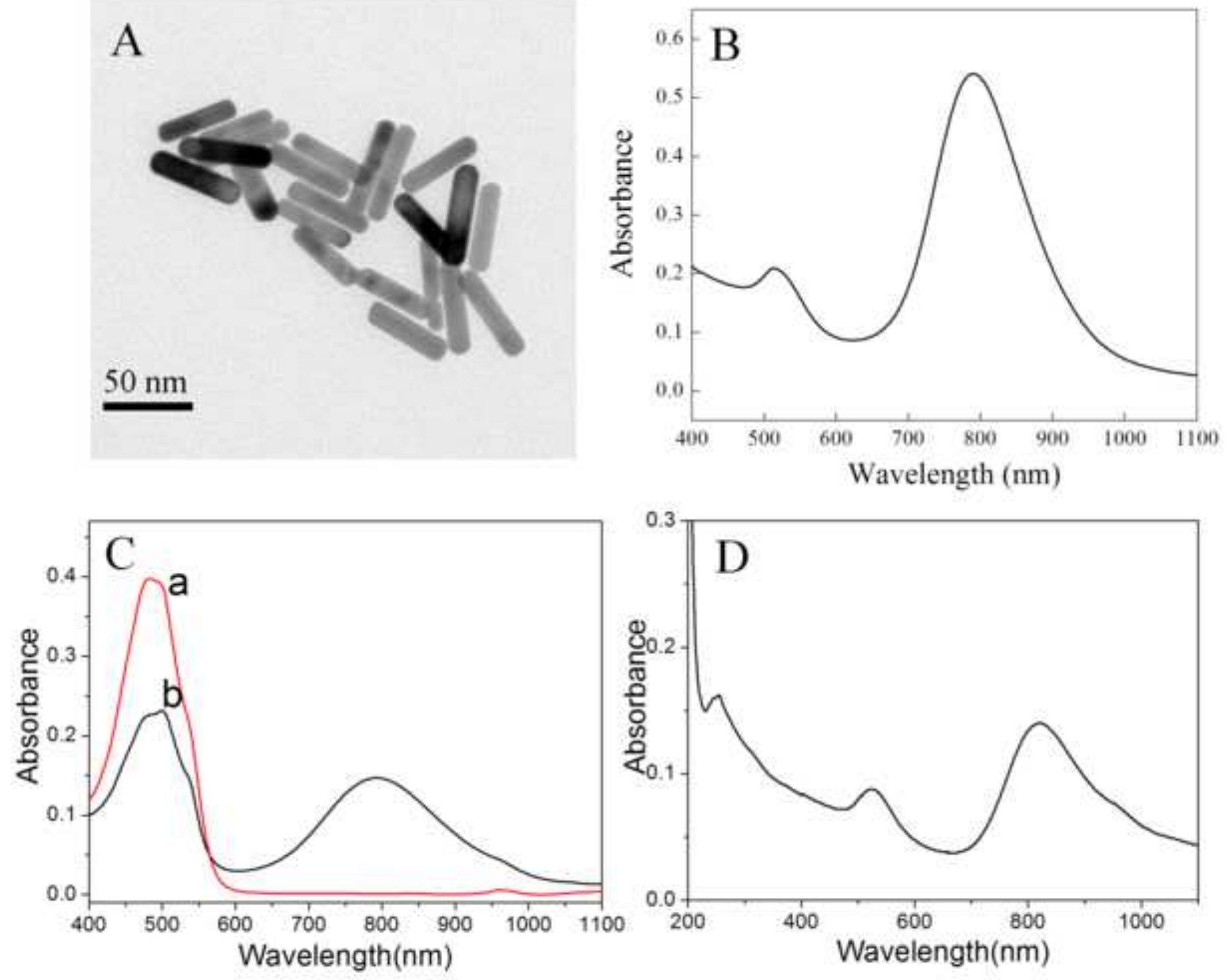

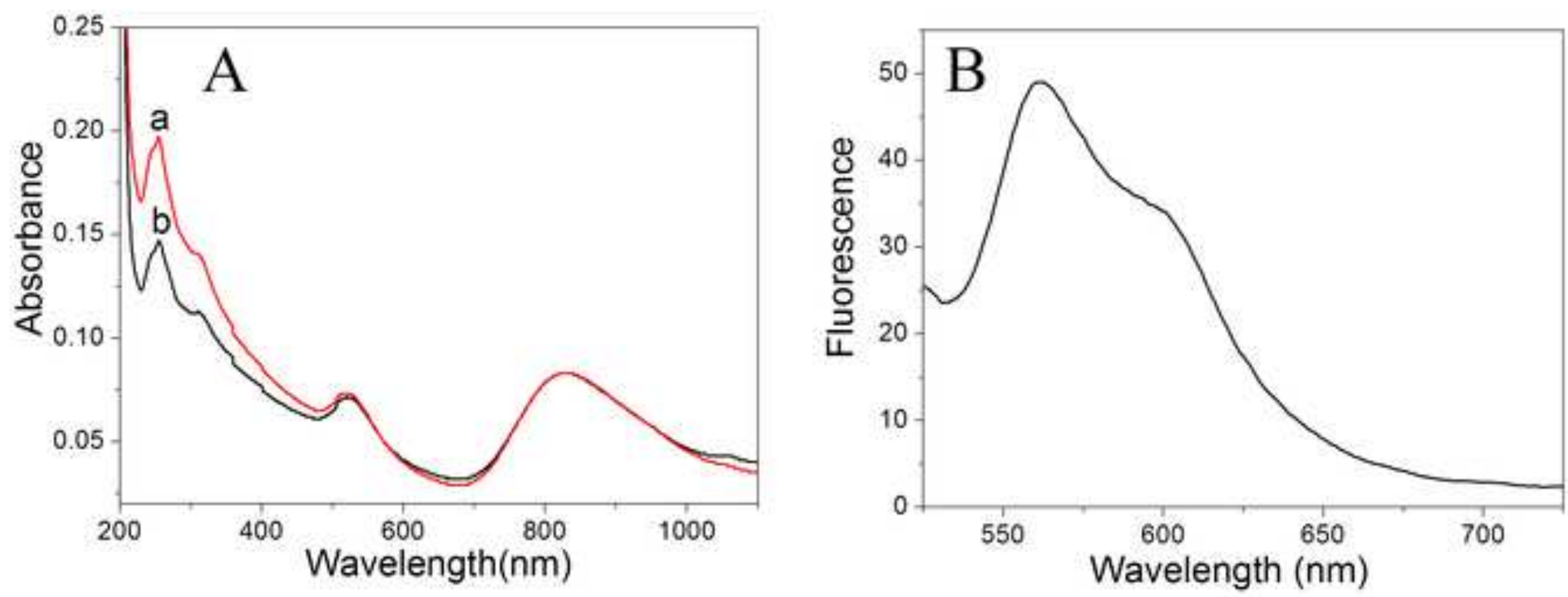

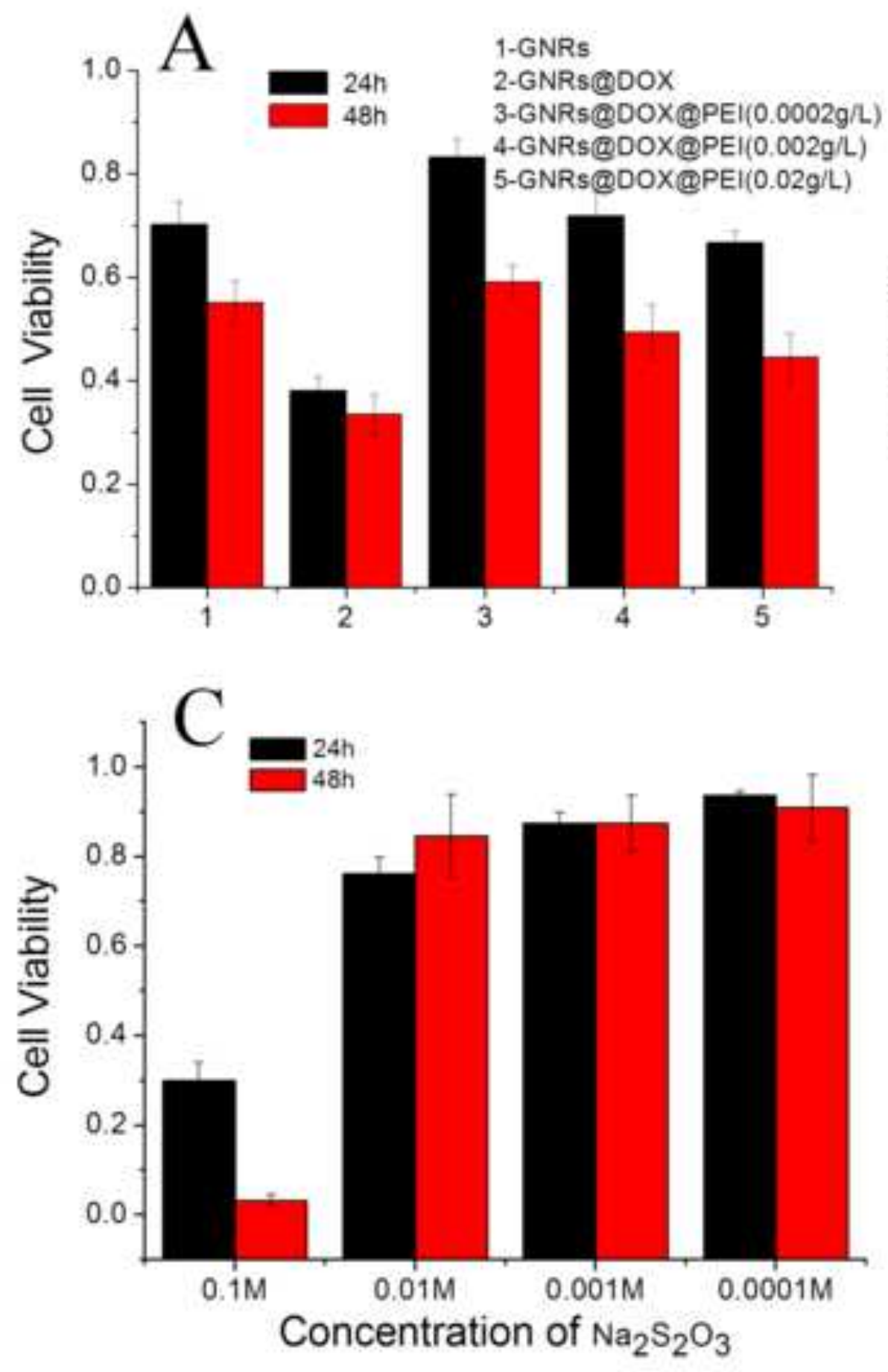

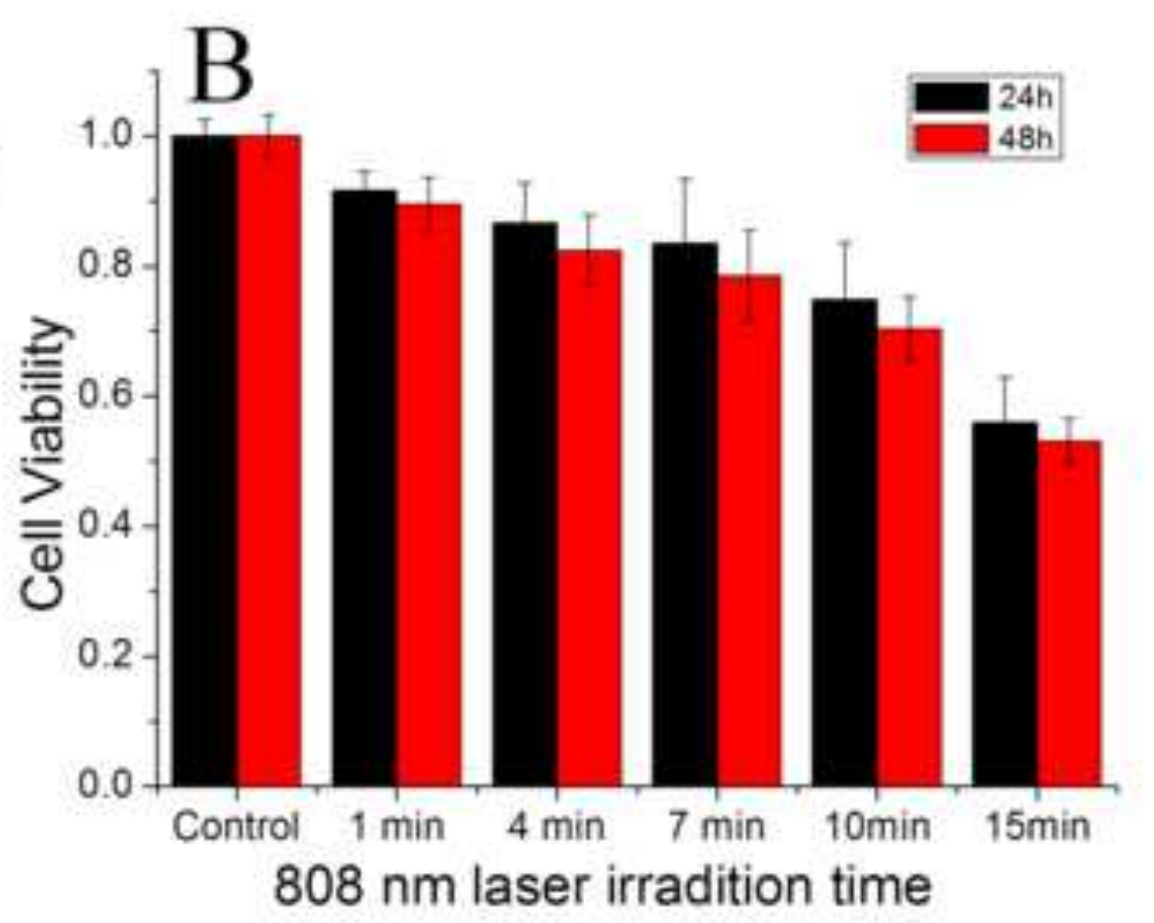

$808 \mathrm{~nm}$ laser irradition time 


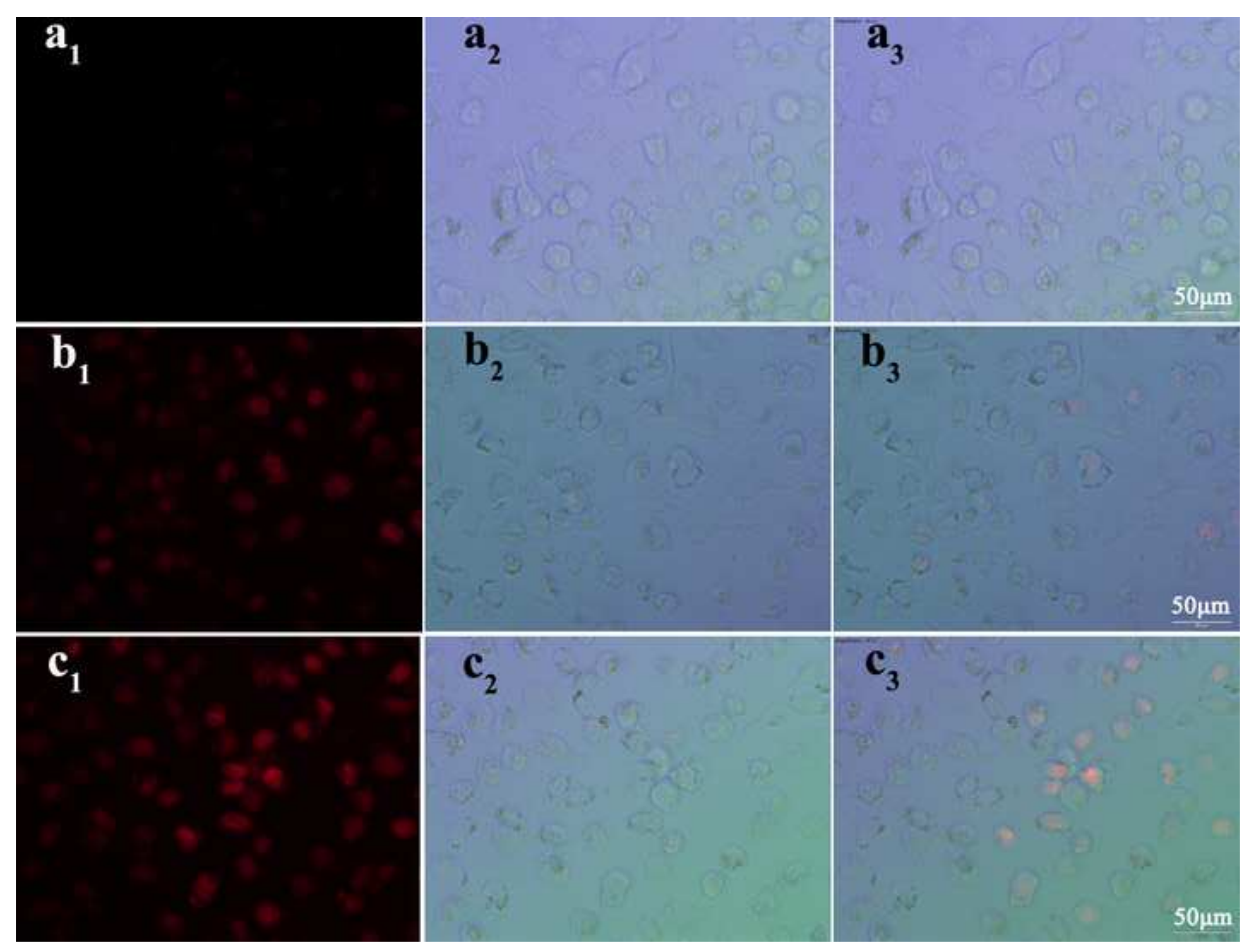




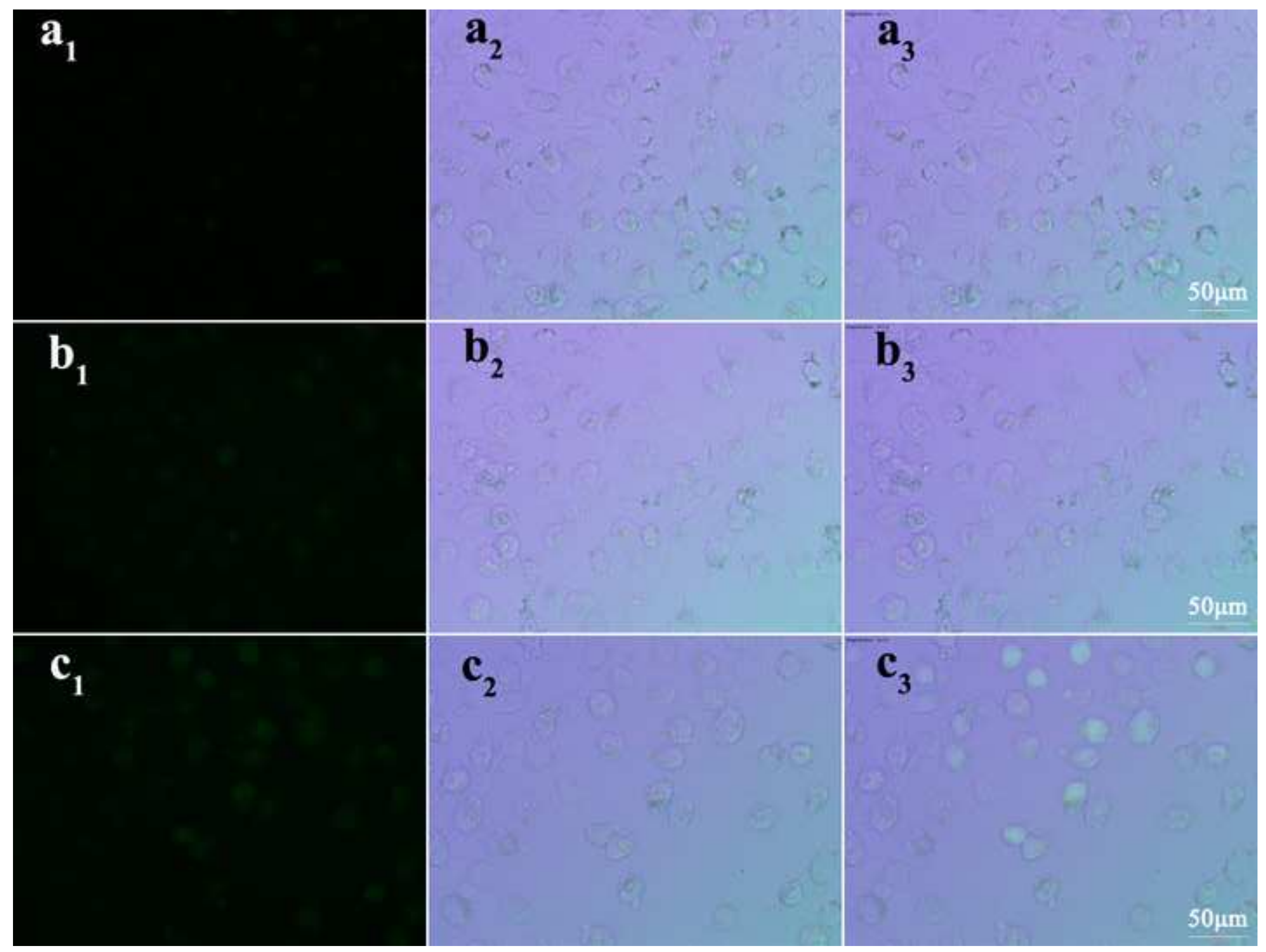


